\title{
Perceived Barriers to Physical Activity and Related Factors in Spanish University Students
}

\author{
Rodolfo Iván Martínez-Lemos ${ }^{1}$, Anna María Puig-Ribera² ${ }^{2}$, Oscar García-García ${ }^{1}$ \\ ${ }^{1}$ Special Learning Department, University of Vigo, Pontevedra, Spain \\ ${ }^{2}$ Departament de Ciències de l'Activitat Física, Universitat de Vic, Barcelona, Spain \\ Email: ivanmartinez@uvigo.es, annam.puig@uvic.cat, oscargarcia@uvigo.es
}

Received 18 February 2014; revised 19 March 2014; accepted 29 March 2014

Copyright (C) 2014 by authors and Scientific Research Publishing Inc.

This work is licensed under the Creative Commons Attribution International License (CC BY). http://creativecommons.org/licenses/by/4.0/

\section{(c) (i) Open Access}

\begin{abstract}
Objective: The purpose of this study was to identify the influence of readiness of change for physical activity (PA), sociodemographic factors, lifestyle and physical activity status (PAS) on perceived barriers among Spanish university students. Participants: Seven hundred and seventy two $(n=772)$ men and women ages 17 - 39 at a north-west regional university in Spain participated in the study. Methods: The International Physical Activity Questionnaire, the States of Change for Physical Activity Behaviour Questionnaire and the Self-perceived Barriers for Physical Activity Questionnaire were used. Description, correlation and multiple regression analyses were completed. Results: Participants self-perceived low average-score barriers $(2.6 \pm 1.4$ over 10.0). The 3-higher scores barriers corresponded to "too much work"; "lack of time for exercise" and "laziness". Gender, PAS and self-perceived health were shown to be associated with perceived barriers. Conclusions: University institutions should consider those factors that predict barriers to PA to develop effective intervention programs.
\end{abstract}

\section{Keywords}

University Students; Barriers; Physical Activity

\section{Introduction}

Physical inactivity (PI) is the most prevalent modifiable risk factor for developing cardiovascular disease, hypertension and dyslipidaemia among the adult population [1]. In Europe, inactivity is a widespread lifestyle among the youth (15 - 24 years old), with 50\% - 55\% of teenagers and young adults showing low levels of 
physical activity (PA) [2]. The transition between high school and university have been described as critical periods when PA levels decline during adolescence and activity behaviour starts to slowdown as adults [3]. In Spain, university students have reported a moderate to high prevalence of inactivity (40\% - 60\%), with significant differences in PA levels according to academic disciplines. Lower levels were found among those studying Humanities, Education Sciences and Arts compared to students in Health Sciences, Nursing and Physiotherapy [4]-[6]. However, most students showed a decrease in PA levels at the beginning of the university studies [7]-[9], and an increase of prolonged sitting time spent on academic tasks (8 hours/day) [10]. Most importantly, PI in young adults can persist over time, influence one's activity behaviour as an adult and therefore, negatively affect adult health [11]. Thus, achieving insufficient levels of PA (30 min of daily moderate PA $\geq 85.7$ MET) at university has become a major public health issue [12]. Since the net enrolment university is a growing trend in Spain from the $23.8 \%$ on 2007 to $27.9 \%$ on 2012 [13], it is crucial to design preventive interventions that stop PI in this stage of life [14]. According to the social ecological theory [15], personal health behaviour occurs in the interaction between the individuals, the environment and community in which people live. Therefore, identifying those factors associated with health behaviour in specific target groups is a key issue to develop effective interventions individually tailored for each population. Thus, understanding the reasons why university students do not participate in sufficient PA according to personal, interpersonal, environmental, and social and policy factors is essential. Since perceived barriers to being active are the single main predictor of health behaviour change [16], identifying barriers to PA for university students is a key issue to develop and implement successful PA promotion programs for this group [17]. In Spain, evidence has shown that a high percentage of inactive students (75\%) know the benefits of regular PA [18] [19], that extrinsic motivation predominates in the early Stages of Change (SOC) for PA and, that intrinsic motivation is important for progression towards the maintenance stage [20]. However, barriers for PA have been barely examined in Spanish university students. Consequently, there is scarce data on the development and implementation of effective PA promotion programs in Spanish universities. In this context, the purpose of this study was to identify Spanish university student's perceived barriers to PA and their related factors; sociodemographic characteristics, life style health-related variables, stages of change for PA behaviour and physical activity status (PAS).

\section{Methods}

\subsection{Participants}

The study population consisted of 13.011 students who enrolled at University of Vigo. Sample selection followed a proportional and stratified sampling procedure [21] according to gender and knowledge area representing population of University, as shown Table 1. A 95\% confidence level and a 3.5\% margin of error were adopted for calculating the size of the sample (740 individuals). A total of 1057 students assisting in class in twelve different faculties along three university campus were invited to participate. A randomized procedure was used for drawing lots for the classes within each faculty. The survey was administered directly without preview notice, following a standardized protocol that was repeated. All participants gave their informed and written consent. The study protocol as well as ethical issues were cleared and approved by the ethics committee of the University of Vigo.

\subsection{Instruments}

The International Physical Activity Questionnaire (IPAQ), Spanish short version [22], is a seven-item retrospective and self-report survey to quantify PA along the last week. IPAQ have been tested for reliability and validity [23] with a correlation coefficient $(r=0.34)$ compare with an accelerometer. Following the IPAQ score protocol, PA levels were classified into Low $(<600)$, Moderate $(\geq 600<1500)$ and High $\left(\geq 1500\right.$ MET-min'week $\left.{ }^{-1}\right)$. Three levels were recategorized in two: "sufficiently active" (Moderate and High PA level) and "insufficiently active" (Low PA level). This last was identified as PI. Inactivity was also defined as a score below $150 \mathrm{~min} \cdot \mathrm{wk}^{-1}$ in accordance with the recommendations from the US Surgeon General's Report [24], American College of Sport Medicine and Centres for Disease Control [25].

The States of Change for Physical Activity (SOCPA) Spanish version [26] is a five item self-report survey to addressing attitudes toward currently PA behaviour. SOCPA describe five stage of change behaviour for PA; 1) Precontemplators (PC) are inactive and not thinking of becoming active, 2) Contemplators (C) are inactive but 
Tabla 1. Population and sample of the selected degrees for the study by gender and knowledge areas.

\begin{tabular}{|c|c|c|c|c|}
\hline \multirow{2}{*}{ Stratified variables } & \multicolumn{2}{|c|}{ Population ( $\mathrm{N}=13,011)$} & \multicolumn{2}{|c|}{ Sample $(\mathrm{n}=772)$} \\
\hline & $\mathrm{N}$ & $\%$ & $\mathrm{n}$ & $\%$ \\
\hline \multicolumn{5}{|l|}{ Gender } \\
\hline Females & 7039 & 54.1 & 421 & 53.2 \\
\hline Males & 5972 & 45.9 & 351 & 46.8 \\
\hline \multicolumn{5}{|l|}{ Knowledge areas } \\
\hline Scientific $^{1}$ & 1726 & 13.26 & 104 & 13.47 \\
\hline Humanistic $^{2}$ & 1062 & 8.16 & 66 & 8.54 \\
\hline Technologic ${ }^{3}$ & 4116 & 31.63 & 246 & 31.86 \\
\hline Legal \& Social ${ }^{4}$ & 6107 & 46.93 & 356 & 46.11 \\
\hline
\end{tabular}

are thinking about becoming active, 3) Preparers (P) intend to be physically active in the next month or have unsuccessfully taken action in the past year (not at the recommended levels), 4) Action stage (A) are individuals physically active at the recommended levels but have been active for less than six months, and 5) Maintenance stage (M) are individuals physically active at the recommended levels and have been active for six or more months. Any of the three first stages (PC/C/P) was identified as being inactive.

The Self-perceived barriers for Physical Activity (SPBPA) is a 17 item self-report survey that assesses specific barriers in PA in relation to four sub-scales: 1) Body image \& psychosocial anxiety (5-item); 2) Fatigue \& laziness (3-item); 3) Obligations \& lack of time (3-item); and 4) Environment \& facilities (4-item). The measurements of barriers were constructed as a 10-point likert scale, which scored from 1 to 10 for each statement with higher scores for higher levels of barriers. The SPBPA had been validated for university student population with a Cronbach's alpha value of 0.856 based on test-retest after 12 months [27].

\subsection{Data Analysis}

Descriptive statistics were generated on all variables. A Student $t$ test and one-way ANOVA analysis was used for assess differences and Spearman's rho correlation coefficient was used to determine the degree of relationship between variables. The dependent variable for multiple regression analysis was barriers for PA. The independent variables were 1) socio-demographic characteristics, 2) life style health-related variables and 3) stage of change for PA. After determining which of them were significant through a bivariate correlation analysis was introduced in the following model: age $(0 \leq 21$ years; $1>21$ years), gender $(0=$ female, $1=$ male), tobacco use $(0=$ smoker, 1 = ex-smoker/non-smoker), self-health perception $(0=$ regular/wrong, $1=$ good/very good/ excellent), opinion about PI as cardiovascular risk factor $(0=$ no, $1=$ yes $)$, and readiness of change for PA $(0=$ passive stages, $1=$ active stages). Beta-coefficient $(\beta)$ was used to describe the extent of SD change in SPBPA score if the predictor of interest changed by 1SD (while the other predictors were held constant). $\mathrm{R}^{2}$ was used to describe the variation of SPBF for PA score. SPSS v19 was employed for the analysis at $\mathrm{p}<0.05$.

\section{Results}

A final sample of 772 students, 411 females (53.2\%) and 361 males (46.8\%) with a mean age of $20.6 \pm 3.0$; range 17 - 39 and BMI of $22.5 \pm 10.8 \mathrm{~kg} / \mathrm{m}^{2}$ from three different campus completed the questionnaire $(73.3 \%$ response rate). Table 2 presents the descriptive data on the all variables analysed as well as differences by gender. 
Table 2. Descriptive data on the all variables analysed and differences by gender.

\begin{tabular}{|c|c|c|c|}
\hline Variable & Female $(n=411)$ & Male $(\mathrm{n}=361)$ & Both $\mathrm{N}=772$ \\
\hline \multicolumn{4}{|l|}{ Socio-demographics } \\
\hline \multicolumn{4}{|l|}{ Knowledge area, n (\%) } \\
\hline Scientific & $52(6.7)$ & $52(6.7)$ & $104(13.5)$ \\
\hline Humanistic & $54(7.0)$ & $12(1.6)$ & $66(8.5)$ \\
\hline Technologic & $74(9.6)$ & $172(22.3)$ & 246 (31.9) \\
\hline Legal \& social & $231(29.9)$ & $125(16.2)$ & $356(46.1)$ \\
\hline \multicolumn{4}{|l|}{ Residency, n (\%) } \\
\hline Familiar & $264(34.2)$ & $227(29.4$ & $491(63.6)$ \\
\hline Rent apartment & $112(14.5)$ & 95 (12.3) & 207 (26.8) \\
\hline Hostel or dorm & $35(4.5)$ & $39(5.1)$ & $74(9.6)$ \\
\hline \multicolumn{4}{|l|}{ Household economic, n (\%) } \\
\hline Without income & $301(39.0)$ & 254 (32.9) & 555 (71.9) \\
\hline$<300 € /$ month & $71(9.2)$ & $65(8.4)$ & $136(17.6)$ \\
\hline$\geq 300 € /$ month & $39(5.1)$ & $42(5.4)$ & $81(10.5)$ \\
\hline \multicolumn{4}{|l|}{ Occupation, n (\%) } \\
\hline Job & $52(6.7)$ & $49(6.3)$ & $101(13.1)$ \\
\hline Non job & $359(46.5)$ & $312(40.4)$ & $671(86.9)$ \\
\hline \multicolumn{4}{|l|}{ BMI and health related variables } \\
\hline Body Mass Index $\left(\mathrm{kg} / \mathrm{m}^{2}\right)$, mean $(\mathrm{SD})^{*}$ & $21.6( \pm 2.7)$ & $2.6( \pm 2.6)$ & $22.50( \pm 10.82)$ \\
\hline \multicolumn{4}{|l|}{ Tobacco use, n (\%) } \\
\hline Current smoker & $63(8.2)$ & $66(8.5)$ & 129 (16.7) \\
\hline Ex-smoker & $17(2.2)$ & $22(2.8)$ & $39(5.1)$ \\
\hline Non-smoker & 331 (42.9) & $273(35.4)$ & $604(78.2)$ \\
\hline \multicolumn{4}{|l|}{ Self-health perception, n (\%) } \\
\hline Excellent & $18(2.3)$ & $31(4.0)$ & $49(6.3)$ \\
\hline Very good & 89 (11.5) & $124(16.1)$ & $213(27.6)$ \\
\hline Good & $251(32.5)$ & $163(21.1)$ & $414(53.6)$ \\
\hline Regular-wrong & $53(6.9)$ & $43(5.6)$ & $96(12.4)$ \\
\hline \multicolumn{4}{|l|}{ PI as cardiovascular risk factor, n (\%) } \\
\hline Yes & $222(28.8)$ & $191(24.7)$ & $413(53.5)$ \\
\hline Non & $189(24.5)$ & $170(22.0)$ & 359 (46.5) \\
\hline \multicolumn{4}{|l|}{ Physical activity status (PAS) } \\
\hline Energy expenditure (MET-minutes/week), mean (SD) ${ }^{*}$ & $2454(2470)$ & 3895 (3235) & $3128(2941)$ \\
\hline \multicolumn{4}{|l|}{ Levels of PA (MET-minutes/week), n (\%) } \\
\hline Low & $90(11.7)$ & $47(6.1)$ & $136(17.6)$ \\
\hline
\end{tabular}




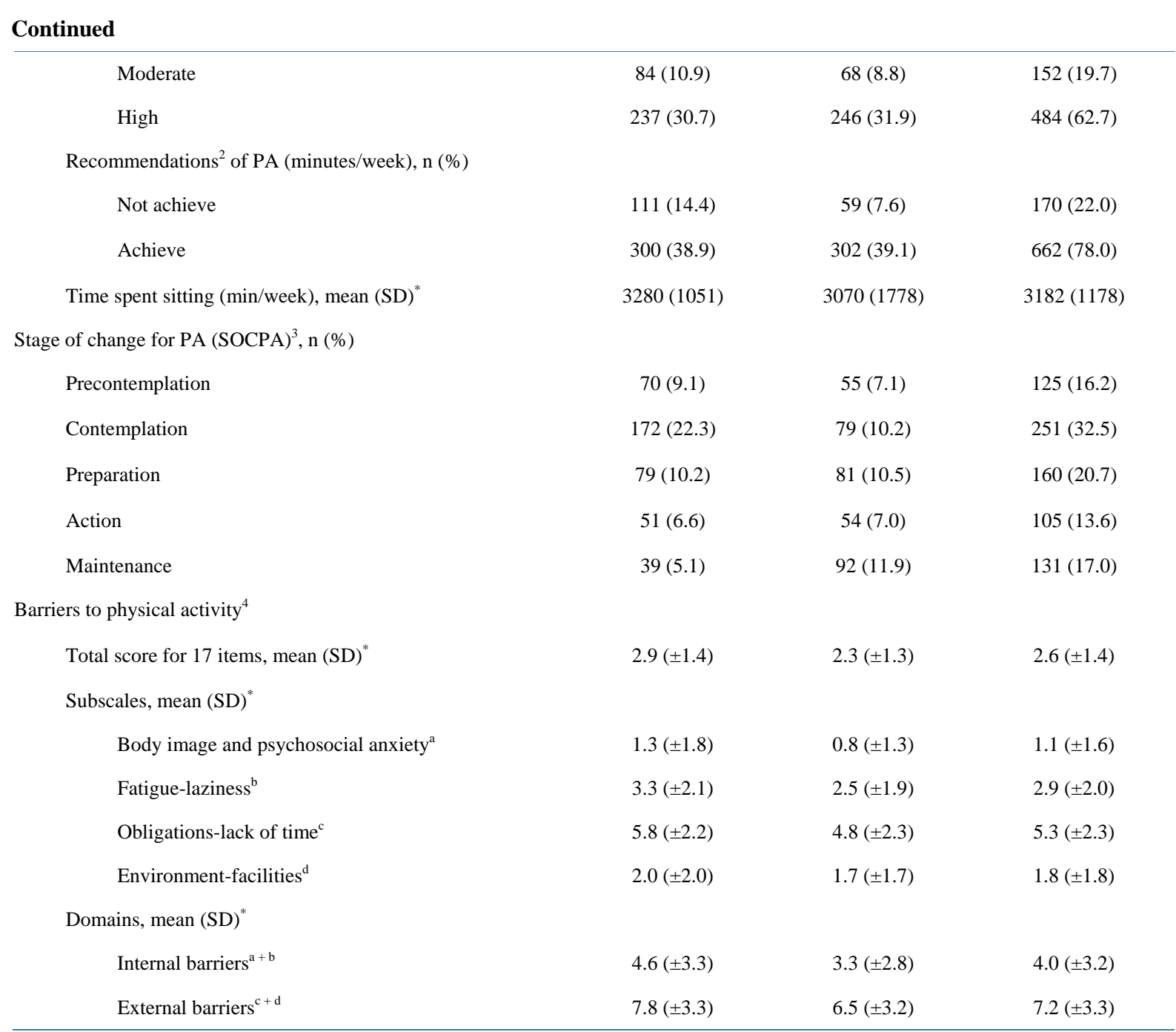

SD: Standard Deviation; ${ }^{*} \mathrm{p}<0.05$ (Independent t-test and one-way ANOVA were used to compare means).

\subsection{Self-Perceived Barriers for PA (SPBPA)}

Table 2 showsthree difference average score barriers for: 1) total barriers (17 items); 2) four subscales barriers and 3) two domains barriers. For total barriers, average score were $2.6 \pm 1.4$ over 10 and the higher scores corresponded to "too much work" (item 4); "laziness" (item 2); "place for me to exercise are too far away" (item 14) and "lack of time for exercise" (item 11). Regarding subscales, the higher scores corresponded to ObligationsLack of Time and for domains, the higher scores corresponded to external barriers. Detailed data are provided in Table 3.

\subsection{The Effects of Sociodemographic on SPBPA}

Table 2 shows that gender had significative effects $(\mathrm{p}<0.05)$ over all barriers scores calculated; so females had significantly higher score barriers for total score, four subscales and two domains. Knowledge area had significative effects $(\mathrm{p}<0.05)$ over some of the barrier calculated, so students of humanistic had significantly higher barriers score $(\mathrm{p}<0.05)$ than any other for total score and two subscales (fatigue-laziness and obligations-lack of time). Table 3 depicts other significative effects $(\mathrm{p}<0.05)$ of sociodemographic, so students that living in rent apartment had the higher score barrier for environment sub-scale, whose without income also had the higher score barrier for fatigue-laziness and environment subscales and for total scores. Finally students that non job also had the higher score barrier for internal domain $(\mathrm{p}<0.05)$. 
Table 3. Mean \pm SD scores of 17 barriers and four subscales of self-report barriers to PA $(n=772)$.

\begin{tabular}{|c|c|c|c|c|c|}
\hline \multirow{2}{*}{ Domain/sub-scale } & \multicolumn{2}{|c|}{ Internal } & \multicolumn{2}{|c|}{ External } & \multirow{2}{*}{ Total (17 items) } \\
\hline & Body Image & Fatigue-Laziness & Obligations & Environment & \\
\hline Variable & $p$ value Mean \pm SD & $p$ value Mean \pm SD & $p$ value Mean $\pm \mathrm{SD}$ & $p$ value Mean \pm SD & $p$ value Mean \pm SD \\
\hline Knowledge area & 0.922 & $<0.001^{*}$ & $0.032^{*}$ & 0.480 & $0.003^{*}$ \\
\hline Scientific & $1.1 \pm 1.4$ & $2.8 \pm 2.0$ & $5.3 \pm 2.1$ & $1.8 \pm 1.8$ & $2.6 \pm 1.4$ \\
\hline Humanistic & $1.1 \pm 1.7$ & $3.9 \pm 2.1$ & $6.0 \pm 1.8$ & $2.0 \pm 1.9$ & $3.1 \pm 1.3$ \\
\hline Technologic & $1.0 \pm 1.6$ & $2.6 \pm 1.9$ & $5.1 \pm 2.2$ & $1.7 \pm 1.9$ & $2.4 \pm 1.4$ \\
\hline Legal \& social & $1.1 \pm 1.6$ & $3.0 \pm 2.0$ & $5.3 \pm 2.5$ & $1.9 \pm 1.8$ & $2.7 \pm 1.4$ \\
\hline Residency & 0.343 & 0.665 & 0.166 & $0.027^{*}$ & 0.630 \\
\hline Familiar & $1.2 \pm 1.6$ & $2.9 \pm 2.1$ & $5.3 \pm 2.4$ & $1.9 \pm 1.8$ & $2.6 \pm 1.4$ \\
\hline Rent apartment & $1.0 \pm 1.6$ & $3.0 \pm 1.9$ & $5.3 \pm 2.1$ & $2.0 \pm 2.0$ & $2.7 \pm 1.3$ \\
\hline Dorm & $1.0 \pm 1.7$ & $2.8 \pm 2.0$ & $5.4 \pm 2.4$ & $1.3 \pm 1.6$ & $2.4 \pm 1.3$ \\
\hline Household economic & 0.080 & $0.010^{*}$ & 0.745 & $0.013^{*}$ & $0.011^{*}$ \\
\hline Without income & $1.2 \pm 1.6$ & $3.0 \pm 2.0$ & $5.4 \pm 2.3$ & $1.9 \pm 1.9$ & $2.7 \pm 1.4$ \\
\hline$<300 €$ & $1.1 \pm 1.6$ & $3.0 \pm 2.1$ & $5.2 \pm 2.3$ & $1.9 \pm 1.8$ & $2.6 \pm 1.5$ \\
\hline$>300 €$ & $0.7 \pm 1.5$ & $2.3 \pm 1.9$ & $5.3 \pm 2.6$ & $1.3 \pm 1.5$ & $2.2 \pm 1.3$ \\
\hline Occupation & $0.012^{*}$ & $0.015^{*}$ & 0.587 & 0.086 & $0.021^{*}$ \\
\hline Job & $0.7 \pm 1.3$ & $2.5 \pm 1.9$ & $5.4 \pm 2.5$ & $1.6 \pm 1.6$ & $2.3 \pm 1.3$ \\
\hline Non job & $1.2 \pm 1.6$ & $3.0 \pm 2.0$ & $5.3 \pm 2.3$ & $1.9 \pm 1.9$ & $2.7 \pm 1.4$ \\
\hline Body mass index & $0.018^{*}$ & 0.067 & 0.214 & 0.673 & 0.101 \\
\hline Underweight & $0.8 \pm 1.0$ & $4.0 \pm 2.4$ & $5.9 \pm 2.1$ & $2.1 \pm 1.8$ & $3.1 \pm 1.0$ \\
\hline Normal & $1.0 \pm 1.6$ & $2.9 \pm 2.0$ & $5.3 \pm 2.3$ & $1.8 \pm 1.9$ & $2.6 \pm 1.4$ \\
\hline Overweight & $1.5 \pm 1.9$ & $3.0 \pm 2.0$ & $5.1 \pm 2.3$ & $1.9 \pm 1.7$ & $2.7 \pm 1.5$ \\
\hline Obese & $1.5 \pm 1.6$ & $3.2 \pm 1.8$ & $5.9 \pm 2.0$ & $2.1 \pm 2.0$ & $3.0 \pm 1.2$ \\
\hline Tobacco use & 0.859 & 0.068 & 0.154 & 0.981 & 0.707 \\
\hline Current smoker & $1.0 \pm 1.6$ & $3.3 \pm 2.0$ & $5.1 \pm 2.3$ & $1.8 \pm 1.9$ & $2.7 \pm 1.3$ \\
\hline Ex-smoker & $1.0 \pm 1.8$ & $2.7 \pm 2.0$ & $4.8 \pm 2.2$ & $1.8 \pm 1.7$ & $2.5 \pm 1.5$ \\
\hline Non-smoker & $1.1 \pm 1.6$ & $2.8 \pm 2.0$ & $5.4 \pm 2.3$ & $1.8 \pm 1.8$ & $2.6 \pm 1.4$ \\
\hline Self-health perception & $<0.001^{*}$ & $<0.001^{*}$ & $<0.001^{*}$ & $0.001^{*}$ & $<0.001^{*}$ \\
\hline Excellent & $0.3 \pm 0.8$ & $1.6 \pm 1.6$ & $4.6 \pm 3.0$ & $1.0 \pm 1.4$ & $1.7 \pm 1.1$ \\
\hline Very good & $0.7 \pm 1.3$ & $2.3 \pm 2.0$ & $4.8 \pm 2.2$ & $1.7 \pm 1.8$ & $2.2 \pm 1.4$ \\
\hline Good & $1.3 \pm 1.7$ & $3.2 \pm 19$ & $5.6 \pm 2.2$ & $1.9 \pm 1.8$ & $2.8 \pm 1.3$ \\
\hline Regular & $1.5 \pm 2.0$ & $3.8 \pm 2.0$ & $5.7 \pm 2.1$ & $2.3 \pm 2.0$ & $3.2 \pm 12.4$ \\
\hline Wrong & $2.4 \pm 3.1$ & $5.2 \pm 3.3$ & $6.7 \pm 1.9$ & $2.0 \pm 0.0$ & $4.0 \pm 1.7$ \\
\hline PI as cardiovascular risk & 0.223 & $0.011^{*}$ & 0.212 & $0.007^{*}$ & 0.909 \\
\hline Yes & $1.2 \pm 1.7$ & $2.7 \pm 2.0$ & $5.4 \pm 2.3$ & $2.0 \pm 1.9$ & $2.6 \pm 1.5$ \\
\hline Non & $1.0 \pm 1.5$ & $3.1 \pm 2.1$ & $5.2 \pm 2.3$ & $1.7 \pm 1.7$ & $2.6 \pm 1.3$ \\
\hline
\end{tabular}




\begin{tabular}{|c|c|c|c|c|c|}
\hline \multicolumn{6}{|l|}{ Continued } \\
\hline PA recommendation & 0.136 & $0.001^{*}$ & $0.003^{*}$ & 0.867 & $0.002^{*}$ \\
\hline$<150 \mathrm{~min} /$ week & $1.3 \pm 1.7$ & $3.4 \pm 2.1$ & $5.8 \pm 2.4$ & $1.9 \pm 1.9$ & $2.9 \pm 1.4$ \\
\hline$\geq 150 \mathrm{~min} /$ week & $1.1 \pm 1.6$ & $2.8 \pm 2.0$ & $5.2 \pm 2.3$ & $1.8 \pm 1.8$ & $2.5 \pm 1.4$ \\
\hline PA level & 0.251 & $0.003^{*}$ & $0.002^{*}$ & 0.857 & $0.004^{*}$ \\
\hline Low & $1.3 \pm 1.7$ & $3.4 \pm 2.0$ & $5.9 \pm 2.1$ & $1.9 \pm 1.9$ & $3.0 \pm 1.4$ \\
\hline Moderate & $1.1 \pm 1.4$ & $2.9 \pm 1.8$ & $5.5 \pm 2.2$ & $1.8 \pm 1.7$ & $2.6 \pm 1.3$ \\
\hline High & $1.0 \pm 1.6$ & $2.8 \pm 2.1$ & $5.1 \pm 2.4$ & $1.8 \pm 1.9$ & $2.5 \pm 1.4$ \\
\hline SOCPA & $<0.001^{*}$ & $<0.001^{*}$ & $<0.001^{*}$ & $0.001^{*}$ & $<0.001^{*}$ \\
\hline Precontemplation & $1.3 \pm 1.6$ & $4.1 \pm 2.2$ & $5.8 \pm 2.3$ & $1.8 \pm 1.9$ & $3.2 \pm 1.3$ \\
\hline Contemplation & $1.4 \pm 1.8$ & $3.5 \pm 1.9$ & $6.1 \pm 2.1$ & $2.0 \pm 2.0$ & $3.1 \pm 1.3$ \\
\hline Preparation & $1.2 \pm 1.6$ & $3.0 \pm 1.8$ & $5.5 \pm 2.1$ & $2.0 \pm 1.8$ & $2.7 \pm 1.3$ \\
\hline Action & $0.6 \pm 1.1$ & $1.9 \pm 1.6$ & $4.5 \pm 2.3$ & $1.7 \pm 1.8$ & $2.0 \pm 1.2$ \\
\hline Maintenance & $0.6 \pm 1.3$ & $1.3 \pm 1.2$ & $3.9 \pm 2.3$ & $1.3 \pm 1.5$ & $1.6 \pm 1.1$ \\
\hline
\end{tabular}

Note: Independent t-test and one-way ANOVA were used to compare the mean of each one of 17 barriers (total) and the mean of each one of four subscales. ${ }^{*} \mathrm{p}<0.05$.

\subsection{The Effects of BMI and Health-Related Variables on SPBPA}

Table 3 shows that categories of self-perceived health had significative effects $(p<0.05)$ over all barriers scores calculated; so to have regular/worse self-perceived health was linked to perceiving more barriers for four subscales, two domains and for total score. However these same differences not could be observed between BMI categories or status tobacco. So be overweight or obese had significative effects $(\mathrm{p}<0.05)$ over internal barriers and be smoker had significative effects $(\mathrm{p}<0.05)$ over fatigue-laziness subscale.

\subsection{The Effects of SOCPA on SPBPA}

Table 3 shows that passive stages of change for PA (PSOCPA) had significative effects $(\mathrm{p}<0.05)$ over all barriers scores calculated; so students in precontemplation and contemplation stages had significantly higher linked to perceiving more barriers for four subscales, two domains and for total score. In addition, the correlation analysis revealed that score for total barriers decreased from precontemplation to the maintenance $\left(r_{s}=-0.42, p\right.$ $<0.001)$.

\subsection{The Effects of PA Status on SPBPA}

Table 3 shows that to achieve the PA for health recommendations and PA level had significative effects ( $<<$ 0.05) over some of the barriers scores calculated; so students that failed to meet the PA for health recommendations and those with low PA level had significantly higher scores for total barriers and for fatigue-laziness and obligations-luck of time subscales $(\mathrm{p}<0.05)$. Regarding the other two PA indicators, the correlation analysis revealed that as energy expenditure (mets/min/week) increase, the score for total barriers decreased significantly $\left(r_{s}=-0.10, p=0.003\right)$ and that as time spent sitting $(\mathrm{min} /$ week$)$ increased, the score for body-image subscale decreased significantly $\left(\mathrm{r}_{\mathrm{s}}=-0.09, \mathrm{p}=0.008\right)$.

\subsection{Predictors of Barriers for Being Active}

Stepwise linear regression, as shown in Table 4, was conducted for asses the ability of three independent variables (SOCPA, gender and self-perceived health) to predict each of one of four sub-scales of SPBPA and all barriers (17 items). For body image and psychosocial anxiety barriers on this order, PSOCPA gender (female) and self-perceived health (regular/wrong) were selected as the significant predictors. They described $6.3 \%(\mathrm{p}<$ 
Table 4. Multiple regression results according to barriers subscales and as a whole $(\mathrm{n}=772)$.

\begin{tabular}{|c|c|c|c|c|c|}
\hline DV: barrier subscale & ID: Predictor (s) & $\beta$ coefficient & $\mathrm{p}$ value (predictor) & $r^{2}$ & $\mathrm{p}$ value \\
\hline \multirow{3}{*}{ Body Image-psychosocial anxiety } & PSOCPA & -0.174 & $* * *$ & \multirow{3}{*}{0.063} & \multirow{3}{*}{$* * *$} \\
\hline & Gender & -0.124 & $* *$ & & \\
\hline & SPH & -0.072 & $*$ & & \\
\hline \multirow{3}{*}{ Fatigue-Laziness } & PSOCPA & -0.393 & $* * *$ & \multirow{3}{*}{0.210} & \multirow{3}{*}{$* * *$} \\
\hline & SPH & -0.119 & $* * *$ & & \\
\hline & Gender & -0.106 & $* *$ & & \\
\hline \multirow{2}{*}{ Obligations-lack of time } & PSOCPA & -0.300 & $* * *$ & \multirow{2}{*}{0.141} & \multirow{2}{*}{$* * *$} \\
\hline & Gender & -0.165 & $* * *$ & & \\
\hline \multirow{2}{*}{ Environment-facilities } & PSOCPA & -0.110 & $* *$ & \multirow{2}{*}{0.025} & \multirow{2}{*}{$* * *$} \\
\hline & SPH & -0.073 & $*$ & & \\
\hline \multirow{3}{*}{ Overall } & PSOCPA & -0.370 & $* * *$ & \multirow{3}{*}{0.208} & \multirow{3}{*}{$* * *$} \\
\hline & Gender & -0.156 & $* * *$ & & \\
\hline & SPH & -0.110 & $* *$ & & \\
\hline
\end{tabular}

PSOCPA: passive stages of change for physical activity (precontemplation, contemplation, preparation); SPH: self-perceived health (regular, wrong); differences; $(*$ : $\mathrm{p}<0.05 ; * *$ : $\mathrm{p}<0.01 ; * * *$ : $\mathrm{p}<0.001)$.

0.001) of the total variance and all of them exhibited negative effects on barriers score. For fatigue-laziness barriers, on this order PSOCPA, self-perceived health and gender were selected as the significant predictors. They described $21.0 \%$ ( $p<0.001$ ) of the total variance and all of them exhibited negative effects on barriers score. For obligations-lack of time, on this order, PSOCPA and gender were selected as the significant predictors. They described $14.1 \%(p<0.001)$ of the total variance and both exhibited negative effects on barriers score. For environment-facilities, on this order, PSOCPA and self-perceived health were selected as the significant predictors. They described 2.5\% ( $\mathrm{p}<0.001$ ) of the total variance and both exhibited negative effects on barriers score. When analysed as a whole, PSOCPA, gender and self-perceived health were selected as the significant predictors. Overall these factors described the $20.8 \%$ ( $p<0.001$ ) of the total variance variation of total barriers and all of them exhibited negative effects on total barriers score. The equation for each sub-scale barrier was listed in Table 5 .

\section{Discussion}

University campus offer key opportunities to promote PA behaviour in students however there is lack of information about the main barriers to PA on this population in Spain. This limits seriously the design of effective and efficient PA promotion programs in this context. The main findings indicated a low score for total barriers, identified higher scores in external barriers, ("too much work", "lack of time” and "laziness”) and confirmed gender, PSOCPA and self-perceived health were associated with barriers to PA. Our findings confirmed that among college students, external barriers prevailed over the internal ones. Regarding external, lack of time has been the most highlighted in our study and similar outcomes can be found in studies carried out between university students in England (UK) (16), Saudi Arabia [28], Egypt [29] and also in Spain [20] [30]. Taking into account that in many cases this student moves away from home, a likely explanation would be the progressive increase in responsibilities, academic task and the difficult to combine studies, social and family commitments with the practice of PA. Regarding internal, fatigue-laziness has been the most highlighted barrier, as was the case in studies with university students in Turkey [31] Malaysia [32] and also Spain [20] [30]. A feasible explanation about this internal perceptions results complex and as it is suggested by some investigations possibly rather more related with the contribution of the school programs of PA to maintain positive attitude towards PA [33] than with the pre-adolescent fitness level [34]. Gender, namely being female, was associated with having more perceived barriers and different studies had confirm that those people perceiving more barriers to PA 
Table 5. Equations of the regression analysis according to the model studied $(n=772)$.

\begin{tabular}{cc}
\hline DV: barrier subscale & Equation \\
\hline Body Image-psychosocial anxiety & $\mathrm{BS}=1.783-0.608$ (PSOCPA) -0.401 (gender) -0.351 (SPH) \\
Fatigue-laziness & $\mathrm{BS}=4.286-1.723(\mathrm{PSOCPA})-0.729(\mathrm{SPH})-0.431$ (gender) \\
Obligations-lack of time & $\mathrm{BS}=6.315-1.502(\mathrm{PSOCPA})-0.761$ (gender) $-0.203(\mathrm{SPH})$ \\
Environment-facilities & $\mathrm{BS}=2.431-0.440(\mathrm{PSOCPA})-0.409(\mathrm{SPH})-0.194$ (gender) \\
Overall & $\mathrm{BS}=3.581-1.130(\mathrm{PSOCPA})-0.468(\mathrm{SPH})-0.439$ (gender) \\
\hline
\end{tabular}

PSOCPA: passive stages of change for physical activity (precontemplation, contemplation, preparation); SPH: self-perceived health (regular, wrong); BS: barriers score.

have more probabilities of becoming inactive [35]. Our findings also showed that female student had a lower PAS than male student with significant differences $(\mathrm{p}<0.05)$ regarding energy expenditure, levels of PA, and achieving the PA recommendations and time spent sitting. Accordingly previous evidence shows that PI among Spanish university students has been widely associated to the female gender in cardiovascular risk studies [4], leisure and free time studies [36], quality of life studies [9] or lifestyles and health studies [6]. SOCPA, namely being in passive stages of change ,were associated with having significantly higher average score for total, internal and external PA barriers and the score relating to barriers decreased significantly across stages of change from inactive to active. This finding is in agreement with previous research results in Saudi [28] and also Spanish university students [20]. On this last, a longitudinal intervention found that PA level not only depended on barriers, but also on motives; suggesting that PA motives are more stable and more related to life-style than barriers, which are more associated to the individual's current situation. Self-health perceived was also found to contribute significantly towards PA barriers. Students with regular/worse self-perceived health were more likely to perceive more barriers than those with good/excellent self-health perceived. This may be related with previous evidence reporting a link between psychology wellness [37] [38] and good perception health [9] with high levels of PA among university students in Spanish. This study relied on a representative sample population of college students of a big medium sized University. This one was believed to be one of the first in Spain to identify the influence of readiness of change for PA on perceived barriers to PA. Therefore is an important contributor to the preview limited evidence on the barriers involved in performing PA. The main limitations of the study are double. First, the study does not allow conclusions about cause and effect. That is, it is not possible to identify whether the low level of PA leads to higher perceived barriers or, on the contrary, to perceive many barriers to practice determines a low level of PA. The second is that barriers to PA and PAS have been self-reported through survey technique that depends on the veracity of the answers.

\section{Conclusion}

The analysis of barriers to PA is an important step before planning any strategy to increase motivation and adherence to the initiation and maintenance of active behaviour in any population. Our findings showed that PAS, gender and self-perceived health were associated with barriers to PA. Therefore policy makers should take into account the analysis of barriers to PA in order to increase PA participation among college students.

\section{References}

[1] Thijssen, D.H., Maiorana A.J., O’Driscoll, G., Cable, N.T., Hopman, M.T. and Green, D.J. (2010) Impact of Inactivity and Exercise on the Vasculature in Humans. European Journal of Applied Physiology, 108, 845-875. http://dx.doi.org/10.1007/s00421-009-1260-x

[2] Varo, J.J., Martinez-Gonzalez, M.A., De Irala-Estevez, J., Kearney, J., Gibney, M. and Martinez, J.A. (2003) Distribution and Determinants of Sedentary Lifestyles in the European Union. International Journal of Epidemiology, 32, 138146. http://dx.doi.org/10.1093/ije/dyg116

[3] Bray, S.R. (2007) Self-Efficacy for Coping with Barriers Helps Students Stay Physically Active during Transition to Their First Year at a University. Research Quarterly for Exercise \& Sport, 78, 61-70. http://dx.doi.org/10.1080/02701367.2007.10599404 
[4] Lemos, S. and Fidalgo, A. (1993) Conductas de riesgos cardiovascular en universitarios. Psicothema, 5, 337-350.

[5] Cancela, J.M. and Ayán, C. (2011) Prevalence and Relationship between Physical Activity and Abnormal Eating Attitudes in Spanish Women University Students in Health and Education Sciences. Revista Española de de Salud Pública, 85, 499-505.

[6] Varela, V., Cancela, J.M., Ayán, C., Martín, V. and Molina, A. (2012) Lifestyle and Health among Spanish University Students: Differences by Gender and Academic Discipline. International Journal of Environmental Research and Public Health, 9, 2728-2741. http://dx.doi.org/10.3390/ijerph9082728

[7] Blasco, T., Capdevila, L., Pintanel, M., Valiente, M. and Cruz, J. (1996) Evolución de los patrones de actividad física en estudiantes universitarios. Revista de Psicología del Deporte, 9, 51-63.

[8] Pérez, D., Requena, C. and Zubiaur, M. (2005) Evolución de motivaciones, actitudes y hábitos de los estudiantes de la facultad de ciencias de la actividad física y del deporte de la Universidad de León. Motricidad. European Journal of Human Movement, 14, 65-79.

[9] Reig, A., Cabrero, J., Ferrer, R. and Richart, M. (2001) La calidad de vida y el estado de salud de los estudiantes universitarios. Biblioteca Virtual Miguel de Cervantes, Alicante.

[10] Chuliá, M., Ferrer, E., Lizama, N., Martin, S. and Monrabal, C. (2005) El sedentarismo en los jóvenes universitarios. Educare21, 17, 125-129.

[11] Telama, R., Yang, X., Viikari, J., Valimaki. I., Wanne, O. and Raitakari, O. (2005) Physical Activity from Childhood to Adulthood: A 21-Year Tracking Study. American Journal of Preventive Medicine, 28, 267-273. http://dx.doi.org/10.1016/j.amepre.2004.12.003

[12] Irwin, J.D. (2004) Prevalence of University Students' Sufficient Physical Activity: A Systematic Review. Perceptual \& Motor Skills, 98, 927-943. http://dx.doi.org/10.2466/pms.98.3.927-943

[13] Ministry of Education, Culture and Sports (2012) Data and Figures of the Spanish University System. General Secretariat of Universities, Madrid.

[14] Haskell, W.L., Lee, I.M., Pate, R.R., Powell, K.E., Blair, S.N. and Franklin, B.A. (2007) Physical Activity and Public Health: Updated Recommendation For Adults from the American College of Sports Medicine and the American Heart Association. Medicine \& Science in Sports \& Exercise, 39, 1423-1434. http://dx.doi.org/10.1249/mss.0b013e3180616b27

[15] Stokols, D., Allen, J. and Bellingham, R.L. (1996) The Social Ecology of Health Promotion: Implications for Research and Practice. American Journal of Health Promotion, 10, 247-251. http://dx.doi.org/10.4278/0890-1171-10.4.247

[16] Lovell, G.P., El Ansari, W. and Parker, J.K. (2010) Perceived Exercise Benefits and Barriers of Non-Exercising Female University Students in the United Kingdom. International Journal of Environmental Research and Public Health, 7, 784-798. http://dx.doi.org/10.3390/ijerph7030784

[17] Zunft, H.J., Friebe, D., Seppelt, B., Widhalm, K., Remaut de Winter, A.M., Vaz de Almeida, M.D., et al. (1999) Perceived Benefits and Barriers to Physical Activity in a Nationally Representative Sample in the European Union. Public Health Nutrition, 2,153-160. http://dx.doi.org/10.1017/S1368980099000208

[18] Sánchez, A., García, F., Landabaso, V. and De Nicolas, L. (1998) Participación en actividad física de una muestra universitaria a partir del modelo de las etapas de cambio en el ejercicio físico: Un estudio piloto. Revista de Psicologia del Deportee, 7, 233-245.

[19] Astudillo, C. and Rojas, M. (2006) Autoeficacia y disposición al cambio para la realización de actividad física en estudiantes universitarios. Actacolombiana de Psicología, 9, 41-49.

[20] Capdevila, L., Niñerola, J., Cruz, J., Losilla, J.M., Parrado, E., Pintanel, M., et al. (2007) Exercise Motivation in University Community Members: A Behavioural Intervention. Psicothema, 19, 250-255.

[21] Thomas, J. and Nelson, J. (2007) Introdución a la investigación en actividad física. Métodos de investigación en actividadfísica, Paidotribo, Barcelona.

[22] Gine, M., Martin, C., Martin, C., Puig, A., Anton, J.J., Guiu, A. et al. (2009) Referral from Primary Care to a Physical Activity Programme: Establishing Long-Term Adherence? A Randomized Controlled Trial. Rationale and Study Design. BMC Public Health, 22, 9-31.

[23] Craig, C.L., Marshall, A.L., Sjöström, M., Bauman, A.E., Booth, M.L., Ainsworth, B.E., et al. (2003) International Physical Activity Questionnaire: 12-Country Reliability and Validity. Medicine \& Science in Sports \& Exercise, 35, 1381-1395. http://dx.doi.org/10.1249/01.MSS.0000078924.61453.FB

[24] U.S. Department of Health and Human Services (1996) Physical Activity and Health: A Report of the Surgeon General.

[25] Pate, R.R., Pratt, M., Blair, S.N., Haskell, W.L., Macera, C.A., Bouchard, C., et al. (1995) Physical Activity and Public health. A Recommendation from the Centers for Disease Control and Prevention and the American College of Sports 
Medicine. Journal of the American Medical Association, 273, 402-407. http://dx.doi.org/10.1001/jama.1995.03520290054029

[26] Puig, A., McKenna, J. and Riddoch, C. (2005) Attitudes and Practices of Physicians and Nurses Regarding Physical Activity Promotion in the Catalan Primary Health-Care System. European Journal of Public Health, 15,569-575. http://dx.doi.org/10.1093/eurpub/cki045

[27] Niñerola, J., Capdevila, L. and Pintanel, M. (2006) Barreras Percibidas y actividad física: El autoinforme de barreras para la práctica de ejercicio físico. Revista de Psicologia del Deporte, 15, 53-69.

[28] Gawwad, E.S. (2008) Stages of Change in Physical Activity, Self-Efficacy and Decisional Balance among Saudi University Students. Journal of Family and Community, 15, 107-115.

[29] El-Gilany, A.H., Badawi, K., El-Khawaga, G. and Awadalla, N. (2011) Physical Activity Profile of Students in Mansoura University. Eastern Mediterranean Health Journal, 17, 694-702.

[30] Gómez, M., Gallegos, A.G. and Extremera, A.B. (2010) Perceived Barriers by University Students in the Practice of Physical Activities. Journal of Sports Science and Medicine, 9, 374-381.

[31] Daskapan, A., Handan, E. and Eker, L. (2006) Perceived Barriers to Physical Activity in University Students. Journal of Sports Science and Medicine, 5,615-620.

[32] Ibrahim, S., Karim, N.A., Oon, N.L. and Ngah, W.Z. (2013) Perceived Physical Activity Barriers Related to Body Weight Status and Sociodemographic Factors among Malaysian Men in Klang Valley. BMC Public Health, 13, 236246. http://dx.doi.org/10.1186/1471-2458-13-275

[33] Thompson, A.M., Humbert, M.L. and Mirwald, R.L. (2003) A Longitudinal Study of the Impact of Childhood and Adolescent Physical Activity Experiences on Adult Physical Activity Perceptions and Behaviors. Qualitative Health Research, 13, 358-377. http://dx.doi.org/10.1177/1049732302250332

[34] Trudeau, F., Laurencelle, L. and Shephard, R.J. (2009) Is Fitness Level in Childhood Associated with Physical Activity Level as an Adult? Pediatric Exercise Science, 21, 329-338.

[35] Sallis, J.F., Hovell, M.F. and Hofstetter, C.R. (1992) Predictors of Adoption and Maintenance of Vigorous Physical Activity in Men and Women. Preventive Medicine, 21, 237-251. http://dx.doi.org/10.1016/0091-7435(92)90022-A

[36] Rodriguez, J. and Agulló, E. (1999) Lifestyles, Culture, Leisure and Free Time of University Students. Psicothema, 11, 247-259.

[37] Jiménez, M.G., Martínez, P., Miró, E. and Sánchez, A.I. (2008) Bienestar psicológico y hábitos saludables: ¿están asociados a la práctica de ejercicio físico? International Journal of Clinical and Health Psychology, 8, 185-202.

[38] Molina ,J., Castillo, I. and Pablos, C. (2007) Bienestar psicológico y práctica deportiva en universitarios. Motricidad. European Journal of Human Movement, 18, 79-91. 